\title{
Subcellular Protein Labeling by a Spatially Restricted Arylamine $\mathrm{N}$-Acetyltransferase
}

\author{
Fleur Kleinpenning, Selma Eising, Tim Berkenbosch, Veronica Garzero, Judith M. Schaart, \\ and Kimberly M. Bonger*(i)
}

Department of Biomolecular Chemistry, Institute of Molecules and Materials, Radboud University, Nijmegen, Heyendaalseweg 135, 6525 AJ, The Netherlands

\section{Supporting Information}

ABSTRACT: Mapping proteins at a specific subcellular location is essential to gaining detailed insight on local protein dynamics. We have developed an enzymatic strategy to label proteins on a subcellular level using arylamine $N$-acetyltransferase (NAT). The NAT enzyme activates an arylhydroxamic acid functionality into a nitrenium ion that reacts fast, covalently, and under neutral conditions with nucleophilic residues of neighboring proteins. The electron density on the aromatic ring proved important for probe activation as strong labeling was only observed with an arylhydroxamic acid bearing an electron donating substituent. We further demonstrate that, using this electron rich arylhydroxamic

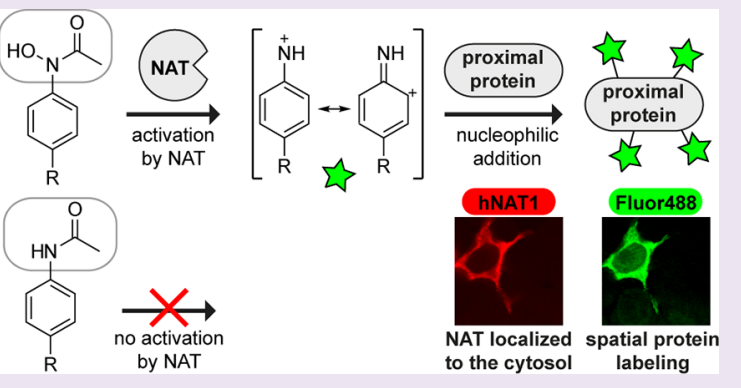
acid, clear labeling was achieved on a subcellular level in living cells that were transfected with a genetically targeted NAT to the nucleus or the cytosol.

\begin{abstract}
T $\mathrm{n}$ order to understand cellular organization and protein homeostasis, it is crucial to obtain proteomic information at a subcellular resolution over time. Common approaches to profile protein content and protein interactions include cell fractionation, immunoprecipitation, and chemical- or photocross-linking. ${ }^{1-3}$ While these techniques are very useful for many applications, it remains a challenge to identify transient, low affinity, or distal interacting proteins of a specific protein of interest (POI). ${ }^{1,2}$ In addition, these approaches often require isolation of the POI from its native cellular environment, leading to the identification of many nonspecific interactors.

To realize proteomic mapping of endogenous proteins within living cells, proximity-dependent protein labeling by a genetically targetable enzyme, such as biotin ligase (BioID) $)^{4,5}$ or an engineered ascorbate peroxidase (APEX), ${ }^{6,7}$ has emerged as a powerful system. BioID is based on an engineered biotin ligase (BirA*), which converts biotin and ATP into a biotin-adenylate mixed anhydride (biotin-AMP). ${ }^{5}$ As biotin-AMP is reactive toward nucleophiles, proteins that reside in close proximity of BirA* will be covalently modified with biotin. While BioID is used successfully for many applications, it has limited use for temporal proteomic profiling due to the long-required labeling times $(6-24 \mathrm{~h}){ }^{6}$ In contrast, APEX generates short-lived free phenoxyl radicals by oxidizing biotin-phenol in the presence of $1 \mathrm{mM}$ of hydrogen peroxide for $1 \mathrm{~min}$ that will react within $<1 \mathrm{~ms}$ with electron-rich amino acids. ${ }^{7,8}$ The biotinylated proteins are then enriched using streptavidin beads and identified by mass spectrometry. ${ }^{8-10}$ Though, the exposure of cells to high levels of peroxide $(1 \mathrm{mM})$, needed for the enzymatic reaction by APEX, might cause adverse effects, such as the induction of a cellular stress response. ${ }^{11}$
\end{abstract}

In order to avoid the use of hydrogen peroxide and still preserve fast labeling times for subcellular protein labeling, we set out to establish a novel enzymatic proximity labeling strategy using arylamine $\mathrm{N}$-acetyltransferase (NAT; Figure 1). NATs are xenobiotic metabolic enzymes catalyzing $N$ - and $O$-acetylation of arylamines and $\mathrm{N}$-hydroxylated arylamines conducting a ping-pong bibi mechanism using acetyl coenzyme A as an acetyl source. ${ }^{12,13}$ Humans have two isoenzymes, hNAT1 and hNAT2, that vary in tissue distributions and substrate specificity. ${ }^{14-16}$

Besides the direct acetylation of arylamines, an additional enzymatic conversion observed for NATs is the catalysis of the $\mathrm{N}, \mathrm{O}$-acetyl transfer of $\mathrm{N}$-acetyl- $\mathrm{N}$-hydroxyarylamines (hydroxamic acids) into $N$-acetoxy-arylamines (Figure $1 \mathrm{~A}) .{ }^{17}$ Depending on the aryl substituents, these $N$-acetoxy esters undergo fast heterolytic $\mathrm{N}-\mathrm{O}$ bond cleavage into nitrenium ions. ${ }^{18,19}$ Although nitrenium ions are relatively stable in aqueous environments, up to microseconds depending on the substituents, they are highly reactive toward nucleophilic residues residing in DNA, RNA, and proteins with rates approaching the diffusion limit. $^{20,21}$ Because of this mechanism and the reactivity toward nucleophilic residues, it has been postulated that these metabolic conversions of arylamines are the onset of the observed carcinogenicity of these compounds. ${ }^{22-25}$ For our studies, we envisioned that we could exploit this unique $\mathrm{N}, \mathrm{O}$-acetyl transfer capacity of NAT for subcellular protein labeling by subjecting synthetic hydroxamic acid probes directly to cells. Subcellular activation of these probe is then established by

Received: February 22, 2018

Accepted: May 31, 2018

Published: May 31, 2018 

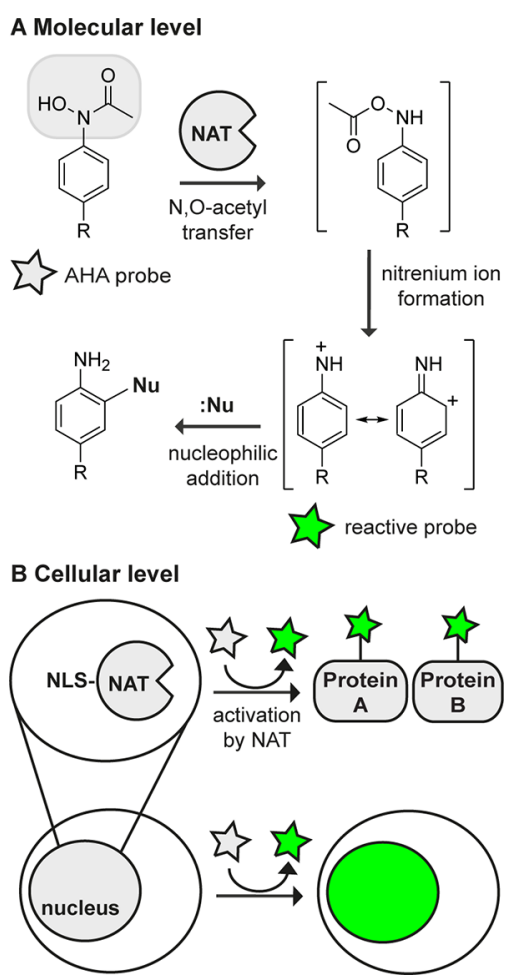

Figure 1. Overview of local protein labeling by the NAT enzyme on a molecular level (A) and a cellular level (B).

overexpressing the NAT enzyme at a specific cellular location of interest.

To evaluate whether the NAT enzyme can be successfully used for labeling of proteins and to assess the influence of electronic factors on the labeling efficiency, ${ }^{18,19}$ we synthesized three different arylhydroxamic acid (AHA) containing probes that varied in the electron donating and withdrawing properties of the linker used to connect the AHA active group to an azide moiety (active probes 1, 3, and 5; Figure $2 \mathrm{~B}$ and $\mathrm{C}$ ). Azides are well-known handles that can be used for visualization of the labeled proteins using established bioorthogonal chemistries, including the copper(I)-catalyzed alkyne-azide cycloaddition (CuAAC) and the strain-promoted alkyne-azide cycloaddition (SPAAC) ${ }^{26}$ In addition, we synthesized a set of structurally similar probes containing an acetamide, lacking the hydroxyl functionality (control probes 2, 4, and 6, Figure $2 \mathrm{~B}$ and $\mathrm{C}$ ). As the hydroxyl is essential for the $N, O$-acetyl transfer by NAT, we use these as control probes in our experiments as nitrenium ion formation is impeded.

The AHA probes were obtained in reasonable to good yields starting from iodophenyl building blocks containing the different azide linkers, using a copper-mediated Ullman-type coupling to THP-protected $N$-hydroxy acetamide in heated DMF (Figure 2B, Supporting Information). ${ }^{27}$ Other attempts to obtain the hydroxamic acid functionality, such as a partial reduction of a nitro group followed by acetylation $^{28-30}$ or the Pd-catalyzed BuchwaldHartwich amination, ${ }^{31,32}$ proved less satisfactory. Removal of the THP protecting group afforded active probes $\mathbf{1}, \mathbf{3}$, and $\mathbf{5}$ in good yields. Control probes 2,4 , and 6 were obtained after a similar Ullman-type reaction using the acetamide.

Having the probes in hand, we started to explore the ability of hNAT1 to activate the AHA probes for covalent protein modification in vitro (Figure 2A). First, His-tagged hNAT1 was expressed in E. coli and partly purified using $\mathrm{Ni}^{2+}$ NTA affinity chromatography (Figure S1). Subsequently, activation of probes 1-6 with the hNAT1 eluate was followed in time and the protein labeling was visualized by the SPAAC reaction using DBCO-Cy5.5 9 (Figures 2E and S2). To our delight, protein labeling of the hNAT1 eluate was evidenced within minutes using the hydroxamic acid 1, containing an electron-donating ether linkage. Significant lower labeling was observed using active probes 3 and $\mathbf{5}$, whereas negligible labeling was detected by incubating hNAT 1 with the control probes 2,4 , and $\mathbf{6}$.

We next determined the amount of protein that is labeled by the AHA probes. For this, we incubated semipurified hNAT1 with AHA reactive probe 7 , containing a biotin moiety (see Supporting Information), and enriched the labeled proteins using streptavidin beads. Similar to the AHA reactive probe 1, high protein labeling was observed within minutes using the AHA probe 7 , while negligible labeling was observed with control probe 8 (Figure 2E and S3A). To our satisfaction, on bead enrichment of the biotinylated proteins was achieved in a concentration-dependent manner, and close to full recovery was observed using $0.5-5 \mathrm{mM}$ of AHA probe 7 under these conditions (Figures $2 \mathrm{~F}$ and $\mathrm{S} 3 \mathrm{~B}$ ).

We were interested in whether the observed protein labeling occurs in a proximity-dependent manner. Therefore, the partialpurified hNAT1 enzyme was spiked into a set of three other purified proteins (e.g., bovine serum albumin, BSA; green fluorescent protein, GFP; and the FK506 binding protein, FKBP) or into human embryonic kidney (HEK-293T) cell lysate (Figure $3 \mathrm{~A}$ ). The protein mixtures were incubated with the most active AHA probe 1 for $1 \mathrm{~h}$, and the labeled proteins were visualized by the SPAAC reaction using DBCO-Cy5.5 9 (Figures 3B and S4). While labeling of proximal proteins was observed in both experimental setups, the hNAT1 enzyme was superiorly labeled, indicating the activated AHA probes favorably reacted with nucleophilic residues in close proximity of the hNAT 1 active site. It should be noted that adding AHA probe 1 to cell lysate in the absence of recombinant hNAT1 also resulted in significant protein labeling, likely due to the endogenously expressed transferase enzymes.

To verify whether our NAT strategy was applicable for labeling in living cells and to assess the level of activation of our probes by endogenously expressed hNAT enzymes, we incubated HEK-293T cells with the AHA probe 1, 3, and 5 as well as the control probes 2, 4, and 6 for $1 \mathrm{~h}$ (Figure 3C and S5). The protein lysate was subjected to the SPAAC reaction using a DBCO-Cy5.5 9 or the CuAAC reaction using a Cy5.5-alkyne 10 and analyzed by SDS-PAGE (Figure 3C and Figure S5A).

Active probe 1 showed significant protein labeling in cells, whereas the control probe $\mathbf{2}$ showed labeling intensities similar to that observed for cells that were not subjected to any probe or in the absence of copper or the Cy5.5-alkyne 10. Protein labeling by AHA probe $\mathbf{1}$ in living cells was already observed within minutes, indicating that this probe is easily diffused into the cell and quickly activated by the NAT enzyme (Figure S6). Although less pronounced labeling was observed for active probes 3 and $\mathbf{5}$ using the purified hNAT 1 protein above, we did observe protein labeling using these probes in living cells (Figures $3 \mathrm{C}$ and $\mathrm{S} 5 \mathrm{~B}$ ). This indicates that the probes can be activated inside living cells by endogenous hNAT1, although we cannot exclude that other potential activating enzymes, such as hNAT2 of arylamine sulfotransferases, ${ }^{33}$ are involved.

More intense signals of the labeled proteins using active probe 1 were observed using DBCO-Cy5.5 9, while the background labeling by the SPAAC reaction was much higher than 

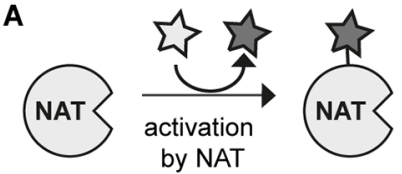

B

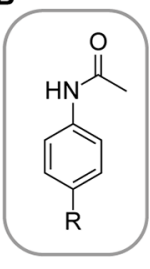

2, 4 6 and 8
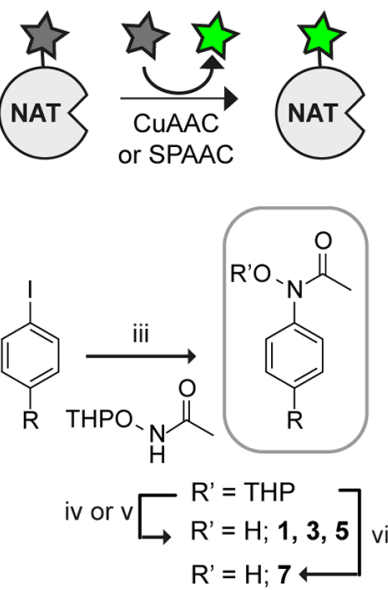

C

$\mathrm{R}=$

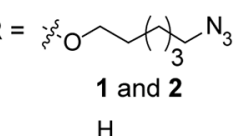

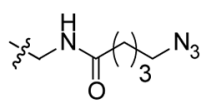

3 and 4

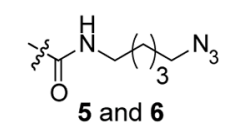<smiles>O=C(C1CC2CCC21)N1Cc2ccccc2C#Cc2ccccc21</smiles>

DBCO-Cy5.59

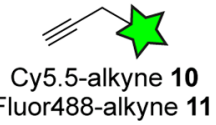

E

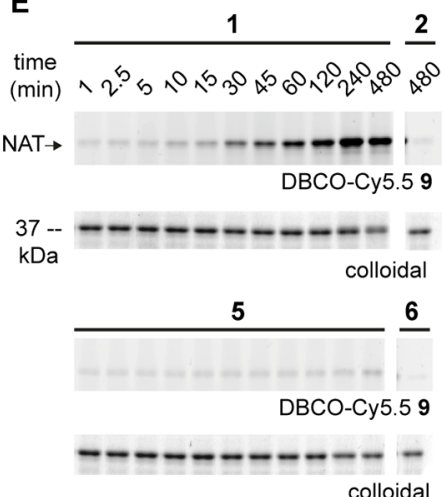

2
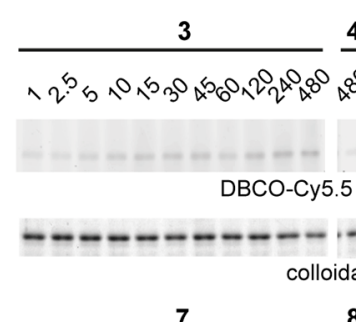

DBCO-Cy5.5 9
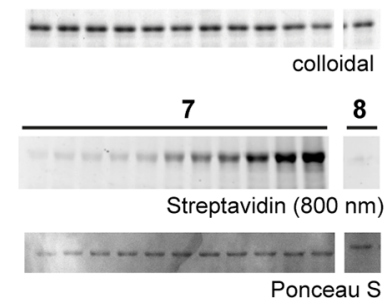

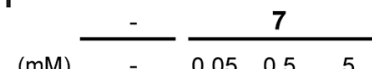

input + - - - - -

FT - + - + - + - + -

beads - - + - + +-+

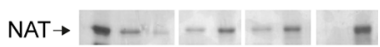

silver stain

$\begin{array}{rllll}\text { NAT (\%) } & 10 & 60 & 85 & 100\end{array}$

Figure 2. (A) Schematic overview of hNAT1 labeling using synthesized AHA probes. (B) Synthetic route and (C) structures of active and control probes 1-8. For probes 2, 4, and 6: (i) CuI, DMEDA, $\mathrm{Cs}_{2} \mathrm{CO}_{3}, \mathrm{DMF}, 80^{\circ} \mathrm{C}, 1-2$ days. For probe 8: (ii, a) CuI, $\mathrm{DMEDA} \mathrm{Cs} \mathrm{CO}_{3}, \mathrm{DMF}^{\circ} 8{ }^{\circ} \mathrm{C}$, 1-2 days. (b) Biotin-alkyne $\mathrm{S12}^{\circ} \mathrm{CuSO}_{4}$, sodium ascorbate, $\mathrm{H}_{2} \mathrm{O}, \mathrm{tBuOH}, \mathrm{DMF}, \mathrm{rt}, 16 \mathrm{~h}$. (iii) CuI, DMEDA, $\mathrm{Cs}_{2} \mathrm{CO}_{3}, \mathrm{DMF}^{\circ} 80^{\circ} \mathrm{C}, 1$ day. For probe 1: (iv) PPTS, EtOH, $55{ }^{\circ} \mathrm{C}, 1$ day. For probe 3 and 5: (v) $4 \mathrm{M} \mathrm{HCl}$ in dioxane, $\mathrm{CH}_{2} \mathrm{Cl}_{2}, 2 \mathrm{~h}$. (vi) Using THP protected probe 1: (a) Biotinalkyne S12, $\mathrm{CuSO}_{4}$, sodium ascorbate, $\mathrm{H} 2 \mathrm{O}, \mathrm{tBuOH}, \mathrm{rt}, 16 \mathrm{~h}$. (b) PTTS, EtOH, $55^{\circ} \mathrm{C}, 16 \mathrm{~h}$. (D) Fluorophore 9-11 used to visualize the labeled proteins. (E) Purified hNAT1 was incubated with probes 1-8 at indicated times and visualized by the SPAAC reaction using DBCO-Cy5.5 7 or by streptavidin IR-800. (F) Enrichment of biotinylated hNAT1 by AHA probe 7 using streptavidin magnetic beads. The percentage indicates the level of protein recovery on the beads relative to the input.

observed for the CuAAC reaction (Figure S5A) and could not be reduced by blocking nucleophilic residues by iodoacetamide treatment. For this reason, we used the CuAAC reaction for visualizing labeled proteins by NAT in further cell experiments.

Unfortunately, protein labeling was not observed by incubating HEK-293T cells with the biotinylated probe 7 (data not shown). Since the hNAT1 enzyme was able to activate the active probe 7 in vitro, the absence of protein biotinylation in living cells might be explained by difficulties of the biotinylated probe to enter the cells.

Subsequently, we evaluated whether our NAT labeling strategy can be used for the subcellular tagging of proteins by overexpressing hNAT1 at a specific cellular region. For this, we targeted the hNAT1, equipped with an HA tag, in HEK-293T cells toward the nucleus using a nuclear localization signal (NLS). As we observed that modification of the C-terminus of NAT inactivates the enzyme (data not shown), ${ }^{16,34}$ we incorporated the localization signal on the N-terminus of the hNAT1 protein. Transient transfection of HEK-293T cells with plasmids encoding the NLS-HA-hNAT1 showed high expression levels and correct localization of the enzyme, as evidenced by confocal microscopy of fixed cells that were stained with antibodies against hNAT and the HA tag (Figure S7). Importantly, the endogenous levels of hNAT in HEK-293T cells were not observed, indicating that endogenous NAT expression levels are low compared to expression levels of the localized hNAT1.

The subcellular labeling potential by nuclear localized hNAT1 was measured for all probes 1-6, whereby the transfected living cells were first incubated with the probes for $1 \mathrm{~h}$, followed by fixation and the CuAAC reaction using Fluor488-alkyne 11 (Figure 4A and Figure S8). To our delight, enhanced subcellular protein labeling was observed in the nucleus using hydroxamic acid $\mathbf{1}$ in the cells overexpressing the NLS-HA-hNAT1. The labeling intensity of active probe 1 correlated with the protein expression levels of the hNAT1 enzyme. Cells that were not transfected with the NLS-HA-hNAT1 did not show pronounced protein labeling. Furthermore, the background of transfected cells treated with control probe 2 was similar to transfected cells that were subjected to the $\mathrm{CuAAC}$ reaction, but not treated with any probe. In contrast to AHA probe 1 , AHA probe 3 did show increased labeling in all cells compared to the control probe 4; however, no subcellular labeling was observed, and the labeling intensities did not correlate with the cellular hNAT1 expression levels (Figure S9). In addition, AHA probe $\mathbf{5}$ showed very similar labeling intensities to that observed for the control probe $\mathbf{6}$, indicating that this probe, as well as active probe 3, are not suitable for use in subcellular labeling applications (Figure S9). 
A

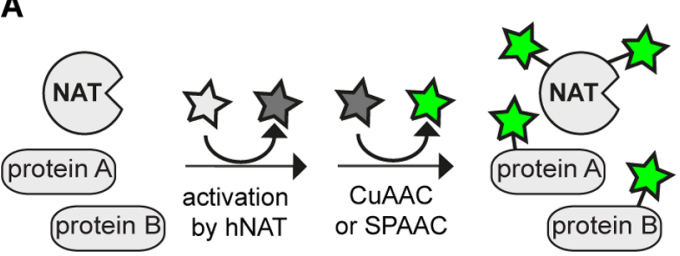

B NAT $\frac{2}{++++\cdots+\cdots} \frac{1}{+-}$

proteins - + - + + - - -

lysate - $-+--_{+}++$

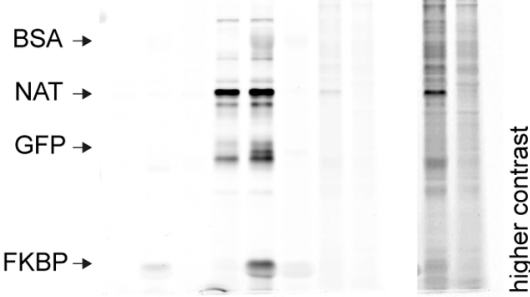

DBCO-Cy5.5 9
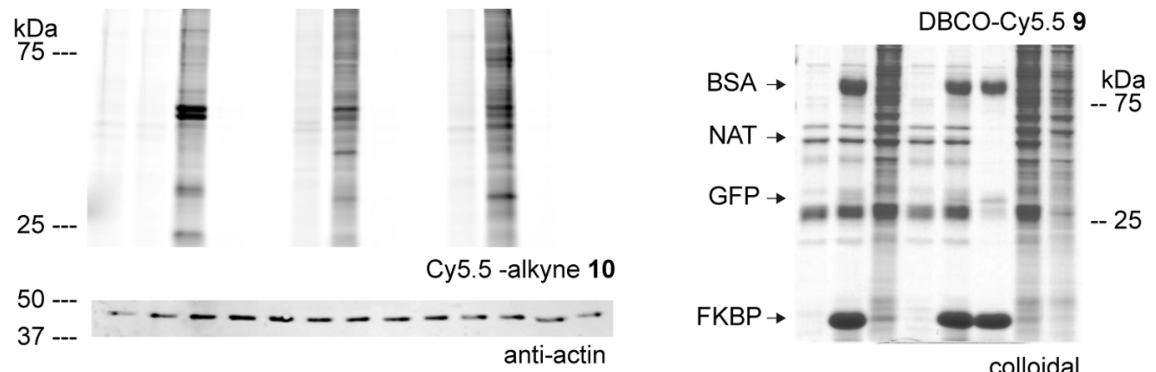

Figure 3. Evaluation of proximal protein labeling by hNAT1. (A) Experimental overview. (B) Semipurified hNAT1 was added to proteins (BSA, GFP, and FKBP) or HEK-293T lysate and incubated with probes $\mathbf{1}$ or $\mathbf{2}$. Proteins were visualized by the SPAAC reaction using DBCO-Cy5.5 9. (C) Living HEK-293T cells were incubated with probes 1-6 for $1 \mathrm{~h}$. Labeled proteins were visualized by the CuAAC reaction using Cy5.5-alkyne 10.

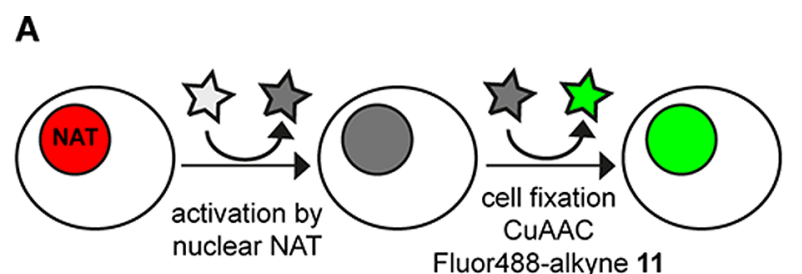

B

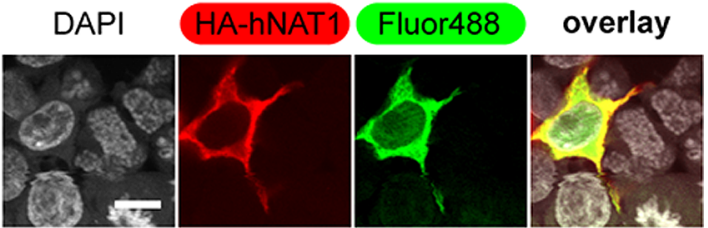

\section{DAPI}
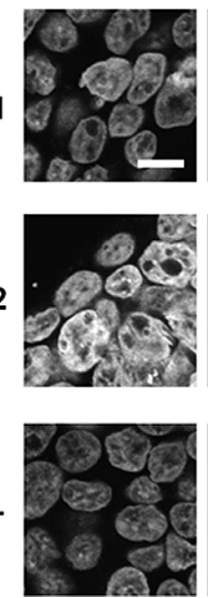
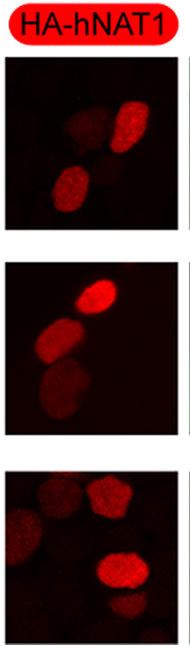
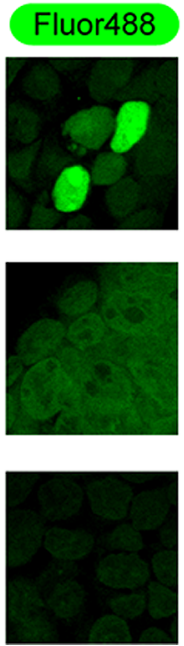

overlay
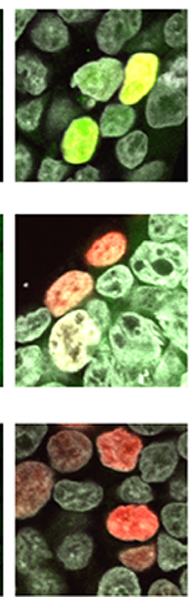

C

5
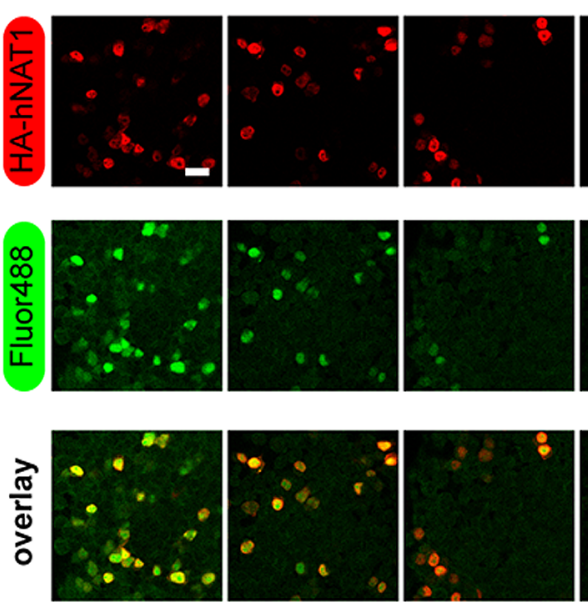

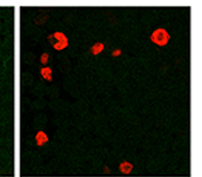

Figure 4. Nuclear and cytosolic labeling was observed by localized hNAT1 using the hydroxamic acid 1 within minutes. (A) NLS-HA-hNAT1 transfected HEK-293T cells were incubated with the active probe $\mathbf{1}$, control probe 2 , or no probe $(-)$ followed by the CuAAC reaction using Fluor488-alkyne 11 (green). HA-hNAT1 was stained against the HA-tag (red) and the nucleus using DAPI (gray). (B) Labeling of NES-HA-hNAT1 transfected cells followed by similar staining as in A. (C) Nuclear protein labeling in time by NLS-HA-hNAT1 transfected HEK-293T cells using the active probe 1 (similar labeling and staining as in A). Scale bar $=25 \mu \mathrm{m}$.

To further validate the general use of the NAT enzyme for subcellular labeling, we targeted the hNAT1 to the cytosol using the nuclear export signal (NES). HEK-293T cells transfected with the cytosolic targeted hNAT1 (NES-HA-hNAT1) were incubated with the probes $\mathbf{1}$ and $\mathbf{2}$ followed by the
CuAAC reaction (Figures 4B and S8). In agreement with the results observed for NLS-HA-hNAT1, enhanced subcellular labeling in the cytosol was observed using probe $\mathbf{1}$ in cells transfected with NES-HA-hNAT1, and intensities correlated to the NAT expression levels. Again, very low protein labeling was 
observed using the control probe 2 , as evidenced with confocal microscopy.

Finally, since subcellular labeling was only observed using active probe $\mathbf{1}$ in cells transfected by NLS-HA-hNAT1, we examined the subcellular protein labeling in time using this probe (Figure 4C and Figure S10). To our satisfaction, initial nuclear protein labeling was observed within $5 \mathrm{~min}$ and increasingly intense subcellular labeling was evidenced over time.

In summary, with this chemoenzymatic labeling strategy based on hNAT1, we show fast and covalent protein labeling at a subcellular level, while avoiding the use of potentially celldisturbing cofactors. hNAT1 recognizes arylhydroxamic acids resulting in the formation of highly reactive nitrenium ions that react covalently with nucleophilic residues in and in close proximity of the hNAT1 enzyme. The electronic properties of the probes seem important for subcellular use. We hypothesize that the increased subcellular labeling using active AHA probe 1 compared to AHA 3 and $\mathbf{5}$ might be explained by the decreased stability of the acetoxy ester intermediate. Due to the electronrich oxygen at the para position of the arylamine probe $\mathbf{1}$, the acetoxy-ester intermediate is likely less stable, resulting in fast nitrenium ion formation. ${ }^{18,19}$ We have used the nitrenium ion activation of probe $\mathbf{1}$ by hNAT1 for clear local labeling in the nucleus as well as the cytosol within minutes in living cells. We envision that this enzymatic NAT labeling approach is suitable for a proteomics setup with high spatial and temporal resolution and thereby holds great promise as an approach to unravel fundamental cell biology questions.

\section{ASSOCIATED CONTENT}

\section{S Supporting Information}

The Supporting Information is available free of charge on the ACS Publications website at DOI: 10.1021/acschembio.8b00178.

Detailed experimental procedures and characterization data; supporting figures, schemes, and tables (PDF)

\section{AUTHOR INFORMATION}

\section{Corresponding Author}

*E-mail: k.bonger@science.ru.nl.

\section{ORCID}

Kimberly M. Bonger: 0000-0001-9498-2620

\section{Notes}

The authors declare no competing financial interest.

\section{ACKNOWLEDGMENTS}

This work was financially supported by the Marie Curie Career Integration Grant and the Institute of Molecules and Materials (IMM) of the Radboud University in Nijmegen. We thank L. Schoonen for technical support and G.J.M. Pruijn for fruitful discussions.

\section{REFERENCES}

(1) Tharkeshwar, A. K., Gevaert, K., and Annaert, W. (2018) Organellar Omics-A Reviving Strategy to Untangle the Biomolecular Complexity of the Cell. Proteomics 18, 1700113.

(2) Pham, N. D., Parker, R. B., and Kohler, J. J. (2013) Photocrosslinking Approaches to Interactome Mapping. Curr. Opin. Chem. Biol. 17, 90-101.

(3) Sinz, A., Arlt, C., Chorev, D., and Sharon, M. (2015) Chemical ross-linking and native mass spectrometry: A fruitful combination for structural biology. Protein Sci. 24, 1193-1209.
(4) Roux, K. J., Kim, D. I., Raida, M., and Burke, B. (2012) A promiscuous biotin ligase fusion protein identifies proximal and interacting proteins in mammalian cells. J. Cell Biol. 196, 801-810.

(5) Kim, D. I., Jensen, S. C., Noble, K. A., KC, B., Roux, K. H., Motamedchaboki, K., and Roux, K. J. (2016) An improved smaller biotin ligase for BioID proximity labeling. Mol. Biol. Cell 27, 11881196.

(6) Rhee, H.-W., Zou, P., Udeshi, N. D., Martell, J. D., Mootha, V. K., Carr, S. A., and Ting, A. Y. (2013) Proteomic mapping of mitochondria in living cells via spatially-restricted enzymatic tagging. Science 339, 1328-1331.

(7) Lam, S. S., Martell, J. D., Kamer, K. J., Deerinck, T. J., Ellisman, M. H., Mootha, V. K., and Ting, A. Y. (2015) Directed evolution of APEX2 for electron microscopy and proximity labeling. Nat. Methods $12,51-54$.

(8) Lee, S.-Y., Kang, M.-G., Park, J.-S., Lee, G., Ting, A. Y., and Rhee, H.-W. (2016) APEX fingerprinting reveals the subcellular localization of proteins of interest. Cell Rep. 15, 1837-1847.

(9) Loh, K. H., Stawski, P. S., Draycott, A. S., Udeshi, N. D., Lehrman, E. K., Wilton, D. K., Svinkina, T., Deerinck, T. J., Ellisman, M. H., Stevens, B., Carr, S. A., and Ting, A. Y. (2016) Proteomic analysis of unbounded cellular compartments: synaptic clefts. Cell 166, 1295-1307.

(10) Han, S., Udeshi, N. D., Deerinck, T. J., Svinkina, T., Ellisman, M. H., Carr, S. A., and Ting, A. Y. (2017) Proximity biotinylation as a method for mapping proteins associated with mtDNA in living cells. Cell Chem. Biol. 24, 404-414.

(11) Kuksal, N., Chalker, J., and Mailloux, R. J. (2017) Progress in understanding the molecular oxygen paradox - function of mitochondrial reactive oxygen species in cell signaling. Biol. Chem. 398, 1209-1227.

(12) Wang, H., Vath, G. M., Gleason, K. J., Hanna, P. E., and Wagner, C. R. (2004) Probing the Mechanism of Hamster Arylamine NAcetyltransferase 2 Acetylation by Active Site Modification, SiteDirected Mutagenesis, and Pre-Steady State and Steady State Kinetic Studies. Biochemistry 43, 8234-8246.

(13) Wang, H., Liu, L., Hanna, P. E., and Wagner, C. R. (2005) Catalytic Mechanism of Hamster Arylamine N-Acetyltransferase 2. Biochemistry 44, 11295-11306.

(14) Kawamura, A., Westwood, I., Wakefield, L., Long, H., Zhang, N., Walters, K., Redfield, C., and Sim, E. (2008) Mouse N-acetyltransferase type 2 , the homologue of human $\mathrm{N}$-acetyltransferase type 1 . Biochem. Pharmacol. 75, 1550-1560.

(15) Wu, H., Dombrovsky, L., Tempel, W., Martin, F., Loppnau, P., Goodfellow, G. H., Grant, D. M., and Plotnikov, A. N. (2007) Structural basis of substrate-binding specificity of human arylamine Nacetyltransferases. J. Biol. Chem. 282, 30189-30197.

(16) Sim, E., Abuhammad, A., and Ryan, A. (2014) Arylamine Nacetyltransferases: From drug metabolism and pharmacogenetics to drug discovery. Br. J. Pharmacol. 171, 2705-2725.

(17) Mangold, B. L., and Hanna, P. E. (1982) Arylhydroxamic acid $\mathrm{N}, \mathrm{O}$-acyltransferase substrates. Acetyl transfer and electrophile generating activity of N-hydroxy-N-(4-alkyl-, 4-alkenyl-, and 4cyclohexylphenyl)acetamides. J. Med. Chem. 25, 630-638.

(18) Novak, M., Kahley, M. J., Eiger, E., Helmick, J. S., and Peters, H. E. (1993) Reactivity and selectivity of nitrenium ions derived from ester derivatives of carcinogenic N-(4-biphenylyl)hydroxylamine and the corresponding hydroxamic acid. J. Am. Chem. Soc. 115, 94539460.

(19) Novak, M., Kahley, M. J., Lin, J., Kennedy, S. A., and Swanegan, L. A. (1994) Reactivity patterns of N-arylnitrenium ions: Lack of correlation with.sigma.t. J. Am. Chem. Soc. 116, 11626-11627.

(20) Kennedy, S. A., Novak, M., and Kolb, B. A. (1997) Reactions of ester derivatives of carcinogenic $\mathrm{N}$-(4-Biphenylyl)hydroxylamine and the corresponding hydroxamic acid with purine nucleosides. J. Am. Chem. Soc. 119, 7654-7664.

(21) Shamovsky, I., Ripa, L., Blomberg, N., Eriksson, L. A., Hansen, P., Mee, C., Tyrchan, C., O’Donovan, M., and Sjö, P. (2012) Theoretical studies of chemical reactivity of metabolically activated 
forms of aromatic amines toward DNA. Chem. Res. Toxicol. 25, 22362252.

(22) Liu, L., Wagner, C. R., and Hanna, P. E. (2009) Isoformselective inactivation of human arylamine $\mathrm{N}$-acetyltransferases by reactive metabolites of carcinogenic arylamines. Chem. Res. Toxicol. 22, 1962-1974.

(23) Sim, E., Walters, K., and Boukouvala, S. (2008) Arylamine Nacetyltransferases: From structure to function. Drug Metab. Rev. 40, $479-510$.

(24) Richter, E. (2015) Biomonitoring of human exposure to arylamines. Front. Biosci., Elite Ed. 7, 222-238.

(25) Murata, M., and Kawanishi, S. (2011) Mechanisms of oxidative DNA damage induced by carcinogenic arylamines. Front. Biosci., Landmark Ed. 16, 1132-1143.

(26) Shieh, P., and Bertozzi, C. R. (2014) Design strategies for bioorthogonal smart probes. Org. Biomol. Chem. 12, 9307-9320.

(27) Jones, K. L., Porzelle, A., Hall, A., Woodrow, M. D., and Tomkinson, N. C. O. (2008) Copper-catalyzed coupling of hydroxylamines with aryl iodides. Org. Lett. 10, 797-800.

(28) Corminboeuf, O., and Renaud, P. (2002) Enantioselective diels-alder reactions with $\mathrm{N}$-hydroxy-N-phenylacrylamide. Org. Lett. 4, 1731-1733.

(29) McKay, C. S., Kennedy, D. C., and Pezacki, J. P. (2009) Studies of multicomponent Kinugasa reactions in aqueous media. Tetrahedron Lett. 50, 1893-1896.

(30) Krüger, S., and Meier, C. (2013) Synthesis of site-specific damaged DNA strands by 8-(acetylarylamino)-2 - deoxyguanosine adducts and effects on various DNA polymerases. Eur. J. Org. Chem. 2013, 1158-1169.

(31) Porzelle, A., Woodrow, M. D., and Tomkinson, N. C. O. (2009) Palladium-catalyzed coupling of hydroxylamines with aryl bromides, chlorides, and iodides. Org. Lett. 11, 233-236.

(32) Beaudoin, D., and Wuest, J. D. (2011) Synthesis of Narylhydroxylamines by Pd-catalyzed coupling. Tetrahedron Lett. 52, 2221-2223.

(33) Chapman, E., Best, M. D., Hanson, S. R., and Wong, C.-H. (2004) Sulfotransferases: structure, mechanism, biological activity, inhibition, and synthetic utility. Angew. Chem., Int. Ed. 43, 3526-3548. (34) Mushtaq, A., Payton, M., and Sim, E. (2002) The $\mathrm{COOH}$ Terminus of Arylamine N-Acetyltransferase from Salmonella typhimurium Controls Enzymic Activity*. J. Biol. Chem. 277, 12175-12181. 